\title{
Action of moguisteine on the activity of tracheobronchial rapidly adapting receptors in the dog
}

\author{
G. Sant'Ambrogio, F.B. Sant'Ambrogio
}

Action of moguisteine on the activity of tracheobronchial rapidly adapting receptors in the dog. G. Sant'Ambrogio, F.B. Sant'Ambrogio. OERS Journals Ltd 1998.

ABSTRACT: We have studied the effects of moguisteine, a new non-narcotic, peripherally acting antitussive compound, on tracheobronchial rapidly adapting irritant receptors (RARs).

Experiments were carried out on dogs anaesthetized with a mixture of urethane and $\alpha$-chloralose, paralysed with gallamine, vagotomized and artificially ventilated. Single unit action potentials identified as originating from tracheobronchial RARs were recorded from the peripheral cut end of the right vagus nerve. The activity of these receptors was recorded together with oesophageal pressure and arterial blood pressure. Fourteen RARs were challenged with moguisteine $\left(200 \mu \mathrm{g}^{-\mathrm{kg}^{-1}}\right.$ i.v. $)$ in $0.4 \%$ dimethylsulphoxide (DMSO) or 0.4\% DMSO alone (vehicle). Receptor activity was recorded before (control) and at $2,5,10,15,20,30$ and 45 min after administration of the challenging compounds.

When the results at intervals of $2,5,10,15$ and $20 \mathrm{~min}$ were averaged for each dog, it was found that moguisteine decreased the mean activity of the 14 receptors to $75 \%$ of the control value $(p<0.05)$; the greatest inhibition occurred 10-20 min after moguisteine administration. DMSO did not significantly affect the activity of these endings. Oesophageal pressure, arterial blood pressure and cardiac frequency were not altered during the experimental procedures.

The overall results indicate the presence of an inhibitory effect of moguisteine on rapidly adapting irritant receptors that could account for the antitussigenic effect of this compound.

Eur Respir J 1998; 11: 339-344.

Moguisteine is an antitussive agent with a novel chemical structure [1]. Its pharmacological activity has been tested on experimental animals and in several clinical trials. In guinea-pigs, moguisteine was found to reduce cough elicited by citric acid inhalation and electrical stimulation of the airway mucosa as effectively as codeine and dextromethorphan [2]. Moguisteine, injected into the cerebral ventricles of guinea-pigs, does not inhibit electrically stimulated cough, which is, instead, effectively blocked by intraventricular codeine: these findings suggest that the antitussive action of moguisteine depends on a peripheral mechanism [3]. Naloxone, a known narcotic antagonist, reverses the antitussive effects of codeine, but not those of moguisteine, indicating that the effects of moguisteine do not involve any interaction with opiate receptors. The antitussive action of moguisteine is also accompanied by clear anti-inflammatory effects in conditions characterized by bronchial hyperreactivity, airway leucocyte recruitment and airway microvascular leakage $[4,5]$. These anti-inflammatory effects of moguisteine have been found to be as strong as those of dexamethasone [4, 5]. Several clinical trials have substantiated the beneficial effects of moguisteine on coughs of various nature: upper airway infection, chronic bronchitis, pulmonary fibrosis and tumours [6-11].

Since cough is a reflex response elicited through the activation of specialized receptors activated by exogenous irritants and/or spontaneously occurring pathological con-
Dept of Physiology and Biophysics, The University of Texas Medical Branch, Galveston, Texas, USA.

Correspondence: G. Sant'Ambrogio

Dept of Physiology and Biophysics

The University of Texas Medical Branch

301 University Blvd

Galveston, TX 77555-0641

USA

Fax: 14097223381

Keywords: Cough

dimethylsulphoxide

irritant receptors

moguisteine

tracheobronchial tree

Received: December 301996

Accepted after revision July 301997

This study was supported by a grant from Boehringer Mannheim Italia SpA, and by an NIH grant HL-20122. ditions, the antitussive action of moguisteine could be viewed as dependent on an inhibitory effect on rapidly adapting irritant receptors (RARs). Indeed, the aim of this study was to investigate the possible effect of moguisteine on the activity of tracheobronchial RARs.

RARs, as first identified by KeLLER and LOESER [12] and later characterized with single fibre recordings by KNOWLTON and LARRABEE [13], represent a group of airway stretch receptors that respond to maintained lung in-flation and deflation with a rapidly adapting discharge at a highly irregular pattern of discharge. The rate of adaptation varies considerably among RARs, with the most rapidly adapting endings responding only during changes in stretch with a behaviour similar to Pacinian corpuscles, showing a clear off-response at the removal of the stim-ulus [14]. RARs are very responsive to intraluminal stim-uli, mechanical probing of the mucosa, inhalation of inert dust, inflammatory mediators and oedema of the airway walls [15]; for this reason they have also been called irritant receptors [16]. The mechanosensitivity (response to inflation) of RARs is second only to that of slowly adapting receptors and higher than that of pulmonary and bronchial C-fibre endings [17].

RARs of similar nature are located superficially within the mucosa of both larynx and tracheobronchial tree [18]. RARs located in the large extrapulmonary tracheobronchial airways (trachea, main stem bronchi and proximal 
lobar bronchi) have receptor fields distributed along the whole circumference, at variance with slowly adapting receptors found only in the membranous posterior wall within the trachealis muscle. These sensory endings are characterized by their scant and irregular discharge, sometimes in synchrony with respiratory events, more frequently with inspiration. Mechanical probing of the receptive field of these endings elicits an activity that subsides rapidly, even when the stimulus is maintained [19-22]. Some of these endings have no noticeable spontaneous discharge, but can be activated by various irritant stimuli of mechanical or chemical nature [23]. Other endings have a spontaneous activity, often with a respiratory and/or cardiovascular modulation that presumably derives from their proximity to structures affected by respiratory and/or cardiovascular motions.

We chose to work with tracheobronchial RARs because, at least in the dog, the cough reflex is significantly stronger and has a higher elicitability from the tracheobronchial region than from the larynx [24].

Our choice of RARs rather than C-fibres was motivated by the observation that, in anaesthetized dogs, mechanically and/or chemically induced cough could be consistently blocked by vagal cooling at temperatures of $6-8^{\circ} \mathrm{C}$ [21], i.e. at temperatures at which $\mathrm{C}$-fibres are thought to remain functional.

\section{Materials and methods}

Experiments were performed on conditioned (parasite free) mongrel dogs of either sex in the $13-16 \mathrm{~kg}$ (mean \pm SEM 14.2 \pm 0.5 ) weight range, purchased from a commercial supplier. The experimental procedures were approv-ed by the Institutional Animal Care and Use Committee (IACUC; protocol number 89-09-283) of the University of Texas Medical Branch at Galveston. The dogs were housed in a controlled environment in the Animal Resources Center of our Institution which is approved by the American Association for Accreditation of Laboratory Animal Care. Prior to each experiment, animals were fasted for $12 \mathrm{~h}$, but allowed free access to water.

The dogs were sedated with ketamine $\left(10 \mathrm{mg} \cdot \mathrm{kg}^{-1}\right.$, i.m. $)$ and anaesthetized with a mixture of urethane and $\alpha$-chloralose (500 mg. $\mathrm{kg}^{-1}$ and $50 \mathrm{mg} \cdot \mathrm{kg}^{-1} i . v$., respectively). The cervical portion of the trachea was exposed and cut longitudinally to insert a large Y-shaped brass cannula. Two polyethylene catheters were inserted into the left femoral vein for administration of further doses of anaesthetics or other drugs, and into the left femoral artery for blood pressure recording. A saline-filled catheter was placed in the mid-portion of the oesophagus to measure oesophageal (intrathoracic) pressure $\left(P_{\text {oes}}\right)$. Both vagus nerves were isolated from the surrounding tissue and carotid arteries, and cut at the level of the cricoid cartilage. Sectioning the vagus nerves leads to a virtual deafferentation of the airways and lungs and, thus, eliminates possible reflex responses that could secondarily modify receptor activity. The dog was then paralysed with gallamine $\left(5 \mathrm{mg} \cdot \mathrm{kg}^{-1}\right)$ and passively ventilated with a respirator (Model 607; Harvard Apparatus, Millis, MA, USA); respiratory parameters were set at levels adequate to maintain end-tidal partial pressure of carbon dioxide $\left(\mathrm{PCO}_{2}\right)$ within a physio- logical range (4.9-5.6 $\mathrm{kPa}(37-42 \mathrm{mmHg}))$. In order to keep lung mechanics constant, the dog was hyperinflated at $1 \mathrm{~h}$ intervals by occluding the outlet of the respirator for 2-3 pump strokes. Adequate levels of anaesthesia and paralysis were maintained by periodic intravenous injection of the anaesthetic mixture $\left(6.3 \mathrm{mg} \cdot \mathrm{kg}^{-1} \alpha\right.$-chloralose and $63.0 \mathrm{mg} \cdot \mathrm{kg}^{-1}$ urethane $)$ and gallamine $\left(2.0 \mathrm{mg} \cdot \mathrm{kg}^{-1}\right)$ at intervals of about $1 \mathrm{~h}$. The maintenance of steady levels of arterial blood pressure and cardiac frequency were considered indicative of the adequacy of anaesthesia.

The peripheral cut end of the right vagus nerve was placed on a round tray with a $3 \mathrm{~cm}$ diameter filled with paraffin oil, and desheathed under a dissecting microscope with the aid of iridectomy scissors and watchmaker's forceps. Single unit action potentials were recorded from thin filaments dissected out of the whole nerve. RARs were identified by their scant and irregular discharge in baseline condition, and by their rapid adaptation in response to a maintained lung inflation. The signal was amplified, displayed on an oscilloscope, and recorded on a thermal array recorder (Gould TA5000; Gould Instrument Systems Inc., Valley View, OH, USA) together with arterial blood pressure and $P$ oes. These parameters were also displayed and recorded on-line on a computer (Dell Dimension $\times$ PS P90; DELL, Austin, TX, USA) at a sampling speed of 4,000 Hz and stored for off-line analysis of the data (WINDAQ/EX; DATAQ Instruments Inc., Akron, OH, USA).

\section{Experimental protocol and data analysis}

Action potentials recorded from RARs either showed a respiratory modulated burst of activity, more frequently in synchrony with the respirator inflation, or were inactive at baseline conditions. The latter type of receptor was activated by inflating the cuff of a Foley catheter introduced into the proximal tracheobronchial airway (lower trachea, main stem bronchus); the inflation was maintained for 1.0$1.3 \mathrm{~s}$. A tracheal or nontracheal (bronchial) location of the receptors with or without a respiratory modulation was determined by direct probing of the trachea [19].

The number of action potentials, either spontaneously occurring or elicited as described, were counted for five to seven respiratory cycles or three cuff inflation-deflation cycles in control condition, and at 2, 5, 10, 15, 20, 30 and $45 \mathrm{~min}$ following bolus injections of moguisteine (200 $\mu \mathrm{g} \cdot \mathrm{kg}^{-1}$ ) in $0.4 \%$ dimethylsulphoxide (DMSO) and DMSO alone (vehicle). When two sets of trials of the same challenge were performed, the data were averaged.

The statistical significance of the changes due to moguisteine in DMSO or DMSO alone was evaluated by averaging the results obtained at 2, 5, 10, 15 and $20 \mathrm{~min}$ for each receptor, and comparing these means to the control values. The Wilcoxon signed rank test was used. Changes were considered significant if at a p-value of less than 0.05 . The choice of this time interval for the evaluation of the effect of moguisteine was based on the time course of its effects; in fact, after the 20 min interval there was a clear tendency for a return toward control values (see below). Moreover, in this time frame all values were available for each receptor and 12 out of 14 endings were affected maximally. Results are presented as mean \pm SEM. 


\section{Drugs and anaesthetics}

The following drugs and anaesthetics were used: Ketaset (ketamine $\mathrm{HCl}$ ); Fort Dodge Laboratories, Inc., Fort Dodge, IA, USA; alpha-chloralose (Sigma Chemical Co.,

Table 1. - Characteristics of the rapidly adapting irritant receptors studied

\begin{tabular}{lcll}
\hline $\begin{array}{l}\text { Dog } \\
\text { No. }\end{array}$ & $\begin{array}{c}\text { Receptor } \\
\text { No. }\end{array}$ & \multicolumn{1}{c}{$\begin{array}{c}\text { Baseline } \\
\text { activity }\end{array}$} & Location \\
\hline 315 & 1a & Respiratory modulation & Tracheal \\
315 & $1 \mathrm{~b}$ & Respiratory modulation & Bronchial \\
316 & 1 & Silent & Tracheal \\
316 & 3 & Silent & Tracheal \\
317 & 1 & Silent & Tracheal \\
318 & 1 & Silent & Tracheal \\
318 & 2 & Respiratory modulation & Bronchial \\
318 & 3 & Respiratory modulation & Bronchial \\
319 & $1 \mathrm{a}$ & Respiratory modulation & Bronchial \\
319 & $1 \mathrm{~b}$ & Silent & Tracheal \\
319 & 2 & Silent & Tracheal \\
333 & 1 & Silent & Tracheal \\
333 & 2 & Respiratory modulation & Tracheal \\
333 & 3 & Respiratory modulation & Bronchial \\
\hline
\end{tabular}
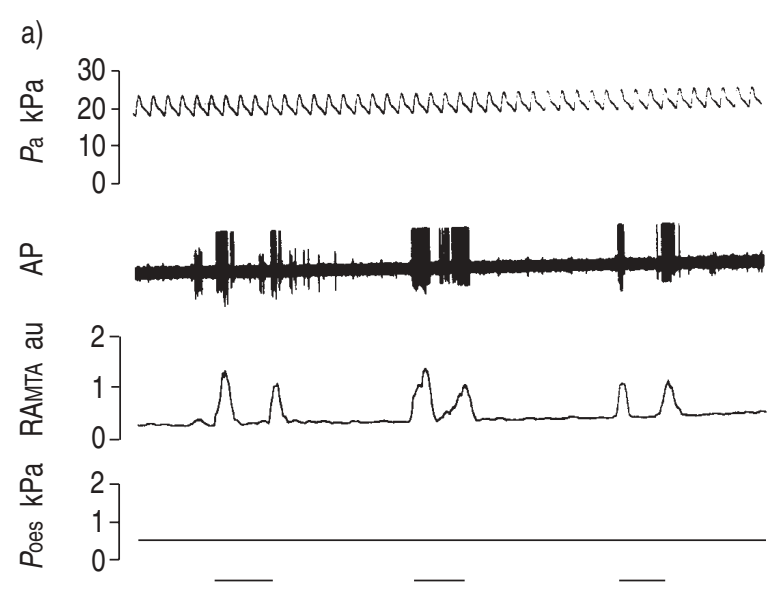

b)
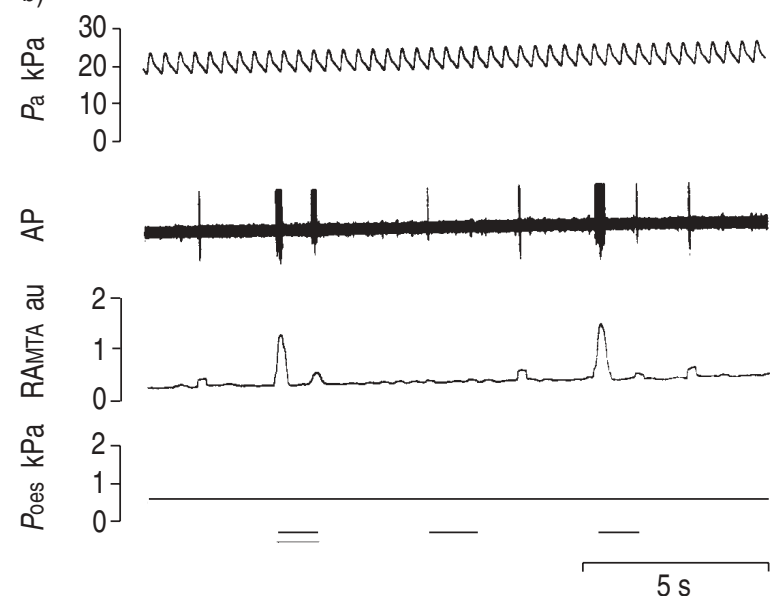

Fig. 1. - Effect of moguisteine on the activity of a nonrespiratory-modulated tracheal rapidly adapting irritant receptors (RARs). a) Before moguisteine; b) 20 min after moguisteine. The activity of the RAR was elicited by inflating and deflating the cuff of a Foley catheter at the receptor field. Note that the respirator was switched off throughout the three inflation-deflation cycles (indicated by the bars). Pa: arterial blood pressure; AP: action potential; RAMTA: receptor activity moving time average; au: arbitrary units; $P_{\text {oes: }}$ oesophageal pressure.
St Louis, MO, USA); urethane (ethyl carbamate; Sigma Chemical Co.); gallamine triethiodide (Sigma Chemical Co.); and moguisteine (ethyl(R,S)-2-(2-methoxyphenoxy) methyl- $\beta$-oxo-3-(1,3 thiazolidine) propanoate; kindly supplied by Boehringer Mannheim, Italy). Moguisteine was prepared as a $1 \mathrm{mg} \cdot \mathrm{mL}^{-1}$ solution in $0.4 \%$ DMSO (Sigma Chemical Co.). As we wanted to administer $200 \mu \mathrm{g} \cdot \mathrm{kg}^{-1}$ moguisteine, we injected $0.2 \mathrm{~mL} \cdot \mathrm{kg}^{-1}$ of this solution. The DMSO vehicle was administered as $0.2 \mathrm{~mL} \cdot \mathrm{kg}^{-1}$ of a $0.4 \%$ solution.

\section{Results}

Fourteen RARs were studied and the location and baseline type of activity of these receptors are presented in table 1 .

Moguisteine decreased the activity of 11 of the 14 endings (figs. 1 and 2, table 2). The maximum decrease in activity of the 14 receptors occurred at 10-20 min after the intravenous injection of moguisteine (table 2 and fig. 3). Thirty minutes after moguisteine administration, the overall activity of the RARs showed a tendency to return toward control values (table 2 and fig. 3 ).

The effect of the challenges on the activity of the 14 receptors was measured, for each ending, as the average of the activity at 2, 5, 10,20 min following moguisteine or
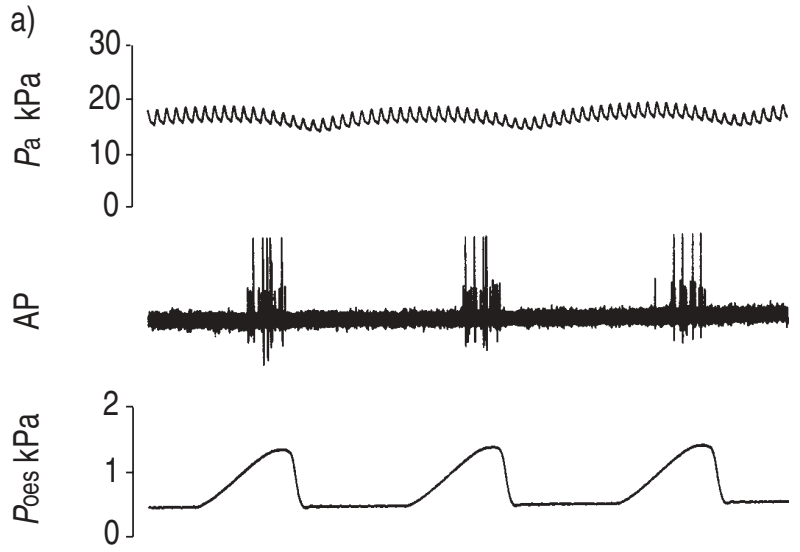

b)
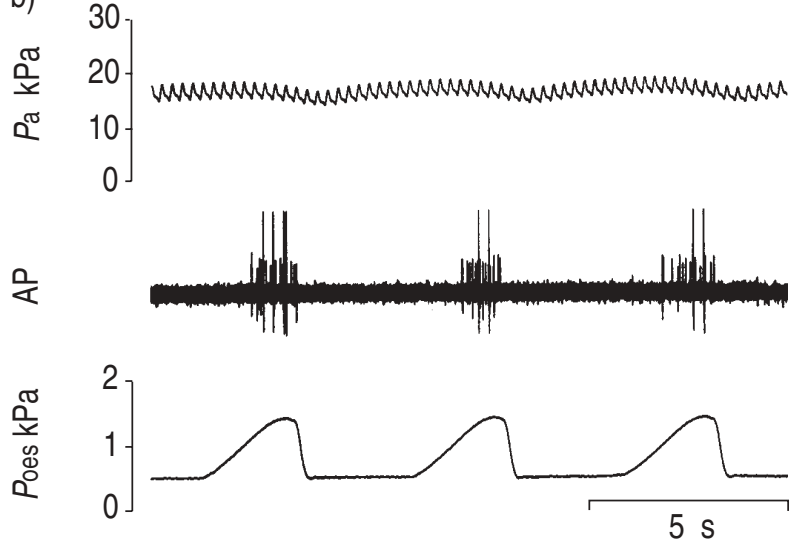

Fig. 2. - Effect of moguisteine on the spontaneous activity of a respiratory modulated bronchial RAR (larger spikes). The smaller spikes are from an unidentified receptor. a) Before moguisteine; b) 20 min after moguisteine. For definitions see legend to figure 1. 
Table 2. - Time course of the effects of moguisteine and dimethylsulphoxide (DMSO)

\begin{tabular}{|c|c|c|c|c|c|c|c|c|c|}
\hline \multirow[b]{2}{*}{ Dog No. } & \multirow[b]{2}{*}{ Receptor No. } & \multicolumn{8}{|c|}{ Action potentials $\mathrm{n}$} \\
\hline & & Control & $2 \min$ & $5 \min$ & $10 \mathrm{~min}$ & $15 \mathrm{~min}$ & $20 \mathrm{~min}$ & $30 \mathrm{~min}$ & $45 \mathrm{~min}$ \\
\hline Moguisteine & $1 \mathrm{a}$ & 13.60 & 12.20 & 11.60 & 17.60 & 12.00 & 9.10 & 11.70 & 11.20 \\
\hline 315 & $1 b$ & 16.25 & 12.80 & 10.80 & 3.80 & 8.40 & 5.20 & 10.50 & 5.60 \\
\hline 315 & 1 & 15.33 & 17.00 & 23.67 & 19.00 & 17.33 & 30.33 & 27.00 & 27.00 \\
\hline 316 & 3 & 81.00 & 49.33 & 72.00 & 61.33 & 53.00 & 62.33 & 61.67 & 65.67 \\
\hline 316 & 1 & 9.62 & 7.82 & 5.17 & 8.12 & 7.47 & 5.50 & 8.16 & 9.20 \\
\hline 317 & 1 & 60.34 & 53.00 & 4.50 & 0.17 & 40.84 & 31.84 & 32.83 & 53.00 \\
\hline 318 & 2 & 2.80 & 3.00 & 2.20 & 2.40 & 2.30 & 2.50 & 2.40 & 2.20 \\
\hline 318 & 3 & 4.60 & 5.02 & 5.24 & 6.09 & 5.67 & 6.80 & 6.70 & 6.10 \\
\hline 318 & $1 \mathrm{a}$ & 6.14 & 6.36 & 7.59 & 2.30 & 2.80 & 2.56 & 2.00 & 3.00 \\
\hline 319 & $1 b$ & 38.84 & 31.50 & 29.67 & 27.33 & 30.00 & 18.17 & 23.00 & 17.00 \\
\hline 319 & 2 & 21.33 & 13.67 & 24.67 & 40.00 & 21.33 & 23.33 & 30.67 & 33.67 \\
\hline 333 & 1 & 27.00 & 19.50 & 13.00 & 16.20 & 12.80 & 13.50 & 17.30 & 14.70 \\
\hline 333 & 2 & 42.33 & 38.00 & 38.00 & 38.70 & 37.30 & 35.00 & 42.70 & 38.30 \\
\hline 333 & 3 & 10.00 & 10.40 & 10.60 & 10.60 & 11.00 & 9.00 & 9.80 & 9.40 \\
\hline \multicolumn{10}{|l|}{ DMSO } \\
\hline 315 & $1 \mathrm{a}$ & 11.20 & 12.40 & 13.60 & 13.00 & 25.75 & 26.40 & 19.00 & \\
\hline 315 & $1 b$ & 4.00 & 11.80 & 9.40 & 3.25 & 11.00 & 10.20 & 16.25 & \\
\hline 316 & 1 & 27.00 & 24.00 & 23.67 & 15.67 & 16.33 & 18.33 & 29.33 & \\
\hline 316 & 3 & 65.67 & 61.00 & 68.67 & 41.00 & 58.00 & 52.00 & 64.67 & \\
\hline 317 & 1 & 11.47 & 10.99 & 10.33 & 11.47 & 11.87 & 11.21 & 11.36 & 8.67 \\
\hline 318 & 1 & 65.00 & 50.33 & 48.33 & 47.33 & 36.33 & 24.00 & 40.67 & 54.00 \\
\hline 318 & 2 & 2.00 & 1.70 & 1.90 & 1.70 & 1.60 & 1.60 & 1.40 & \\
\hline 318 & 3 & 6.10 & 5.67 & 6.25 & 5.70 & 5.50 & 5.80 & 6.78 & 6.30 \\
\hline 319 & $1 \mathrm{a}$ & 4.67 & 6.86 & 5.33 & 5.33 & 5.38 & 9.50 & 8.14 & 6.86 \\
\hline 319 & $1 b$ & 49.67 & 42.33 & 39.00 & 23.67 & 26.00 & 22.67 & 24.67 & 31.33 \\
\hline 319 & 2 & 29.00 & 37.00 & 36.67 & 48.67 & 34.67 & 2.00 & & \\
\hline 333 & 1 & 14.70 & 14.30 & 12.00 & 14.20 & 8.20 & 9.00 & 8.80 & 7.80 \\
\hline 333 & 2 & 38.30 & 40.30 & 43.70 & 48.70 & 47.70 & 49.30 & 45.00 & 41.00 \\
\hline 333 & 3 & 8.80 & 9.80 & 9.60 & 10.80 & 11.40 & 10.80 & 8.60 & 9.40 \\
\hline
\end{tabular}
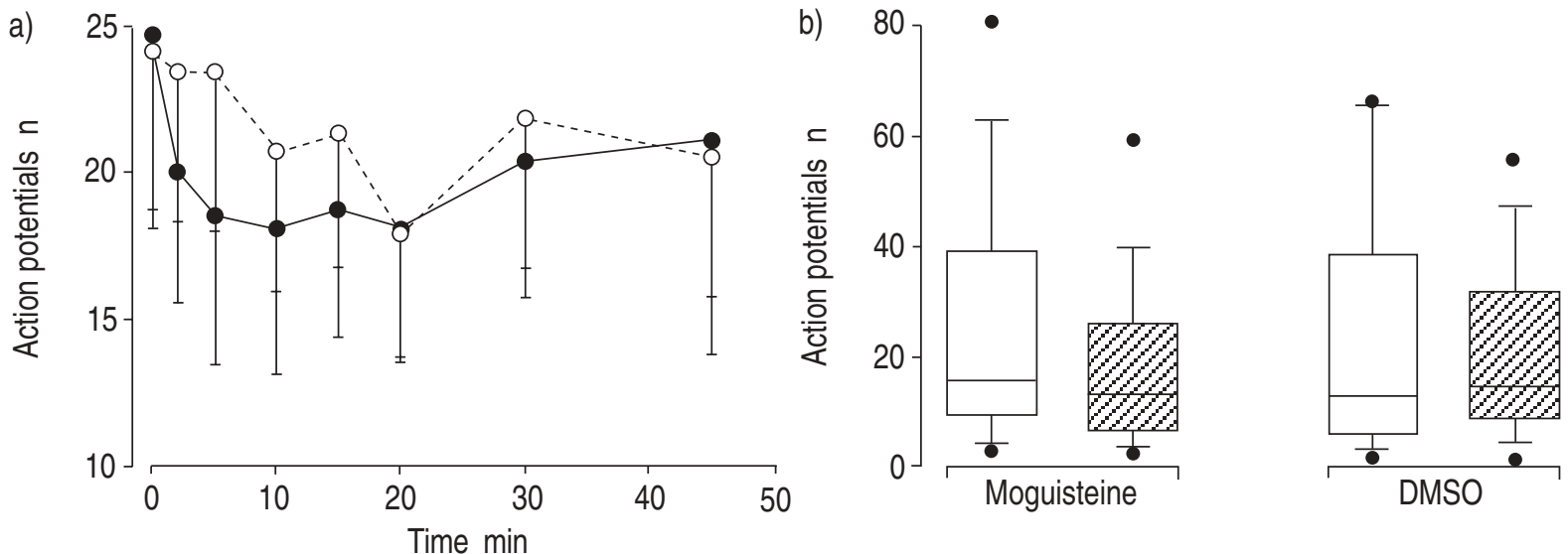

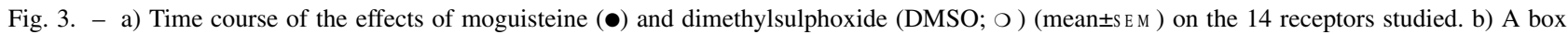
graph representing the activity of the receptors in the control conditions ( $\square$ ) and during the 2-20 min intervals following the administration of the challenges $(Z)$. The horizontal lines of each box represent, from bottom to top, 25 th, 50 th (median) and $75 \%$ percentiles; error bars define the 10 th and 90th percentiles; filled circles represent the lowest and highest values.

DMSO injection. After moguisteine, the average number of action potentials decreased from $24.94 \pm 6.17$ to $18.70 \pm$ $4.20(\mathrm{p}<0.05)$. The challenge with DMSO vehicle did not introduce any statistically significant change (control 24.11 \pm 5.99 , after DMSO 21.43 \pm 4.53 ).

Lack of any significant change in oesophageal pressure swings indicate an essentially stable maintenance of the lung mechanics baseline values; this rules out the possibility of changes in RAR activity attributable to alterations in respiratory mechanics (table 3 ).

The maintenance of stable values of blood pressure and cardiac frequency during the experimental trials (vehicle and moguisteine) is also indicative of a stable physiological condition (table 3 ).

\section{Discussion}

For these experiments, we chose an intravenous administration rather than an oral route, to minimize possible differences in the kinetics of gastro-intestinal absorption of moguisteine among dogs. Furthermore, an intravenous administration of the challenges allows the use of shorter time intervals for the evaluation of receptor activity, keeping the duration of the experiment within a shorter time 
Table 3. - Average values of respiratory $(n=7)$ and cardiovascular $(n=14)$ parameters

\begin{tabular}{|c|c|c|c|c|c|c|c|c|}
\hline & Control & $2 \mathrm{~min}$ & $5 \mathrm{~min}$ & $10 \mathrm{~min}$ & $15 \mathrm{~min}$ & $20 \mathrm{~min}$ & $30 \mathrm{~min}$ & $45 \min$ \\
\hline \multicolumn{9}{|c|}{ Oesophageal pressure $\mathbf{k P a}$} \\
\hline Moguisteine & $1.02 \pm 0.06$ & $1.06 \pm 0.06$ & $1.06 \pm 0.06$ & $1.06 \pm 0.06$ & $1.08 \pm 0.07$ & $1.01 \pm 0.05$ & $0.98 \pm 0.05$ & $0.99 \pm 0.05$ \\
\hline DMSO & $0.98 \pm 0.05$ & $1.05 \pm 0.05$ & $1.06 \pm 0.05$ & $1.02 \pm 0.06$ & $1.04 \pm 0.05$ & $1.08 \pm 0.06$ & $1.10 \pm 0.06$ & $1.02 \pm 0.09$ \\
\hline \multicolumn{9}{|c|}{ Mean blood pressure $\mathbf{k P a}$} \\
\hline Moguisteine & $17.52 \pm 0.64$ & $17.73 \pm 0.57$ & $17.52 \pm 0.53$ & $17.14 \pm 0.52$ & $17.20 \pm 0.56$ & $17.42 \pm 0.45$ & $17.54 \pm 0.39$ & $17.05 \pm 0.42$ \\
\hline DMSO & $16.95 \pm 0.37$ & $16.75 \pm 0.48$ & $17.41 \pm 0.48$ & $17.22 \pm 0.60$ & $17.10 \pm 0.74$ & $17.05 \pm 0.40$ & $17.28 \pm 0.45$ & $17.93 \pm 0.75$ \\
\hline \multicolumn{9}{|c|}{ Cardiac frequency beats·min ${ }^{-1}$} \\
\hline Moguisteine & $168.42 \pm 10.29$ & $172.37 \pm 10.70$ & $170.21 \pm 11.68$ & $168.01 \pm 11.20$ & $168.83 \pm 10.88$ & $174.06 \pm 10.84$ & $166.03 \pm 11.49$ & $166.61 \pm 11.63$ \\
\hline DMSO & $165.53 \pm 12.03$ & $164.77 \pm 11.58$ & $163.86 \pm 11.55$ & $170.25 \pm 12.31$ & $165.67 \pm 12.88$ & $160.50 \pm 12.79$ & $159.92 \pm 13.46$ & $186.84 \pm 17.40$ \\
\hline
\end{tabular}

Oesophageal pressure is reported only for receptors with respiratory modulation. DMSO: dimethylsulphoxide.

frame to the benefit of receptor viability. It is, in fact, often difficult to record from the same receptors for periods in excess of $2 \mathrm{~h}$.

The maximum effects of moguisteine on RAR activity occurred at 10-20 min following injection (table 2 and fig. 3 ). At longer time intervals a tendency to return toward control values became apparent. The average activity of the 14 RARs at intervals from 2-20 min after moguisteine injection decreased to $75 \%$ of the control value, a significant change $(\mathrm{p}<0.05)$. The challenge with DMSO did not introduce any statistically significant change.

RARs of the tracheobronchial tree and larynx showed similar responses to mechanical and some of the chemical irritants and are, therefore, identified under the common denomination of "irritant" receptors [16]. However, within this category of endings we find a wide range of distinctive characteristics, be this in terms of their responsiveness to aqueous solutions of varying osmolarity and composition $[25,26]$ or to particular responses to substances produced within the body (autacoids) or administered experimentally [21, 27, 28]. Since RARs can be activated by known tussigenic stimuli and have a predominant location in areas from which cough can be preferentially induced, a cause-effect relationship between their activation and the subsequent cough response is generally assumed [29]. If this is accepted, it should also follow that agents capable of diminishing the activity of these endings should be effective in controlling the cough reflex. Considerations of this nature have been validated in the case of furosemide which attenuates cough [30] as well as laryngeal RAR activation induced, in the dog, by low chloride solutions [31]. Similar results were found for A $\delta$ fibres, possibly corresponding to RARs, in an in vitro preparation of guinea-pig trachea [32].

Moguisteine failed to reduce the activation of three of the 14 receptor studied. This could be explained in light of the heterogeneous nature of these endings; several observations support this contention. One case in point is the response to distilled water or isosmolar low chloride solutions of laryngeal and tracheal RARs of the dog. At least in the dog, the vast majority of laryngeal RARs are stimulated by water due to their responsiveness to low chloride solutions; in fact, they are also activated by isosmotic solutions lacking chloride ions [26]. On the contrary, only a minority of extrathoracic tracheal RARs of the dog are stimulated by water; some behave as low chloride solution-responsive endings, while others are stimulated by water only (osmo-responsive receptors) [25]. Furthermore, the results of an investigation carried out in dogs on the antitussive properties of furosemide are indicative of a heterogeneous nature of laryngeal RARs; in fact, while the majority of endings reduced their response to isosmotic solution of dextrose after furosemide administration, the rest did not [31]. The response to isosmotic glucose of A $\delta$ fibres in an in vitro preparation of guinea-pig trachea, was also markedly decreased (to $34 \%$ of control) in the presence of furosemide, which had, however, no effect on the response to distilled water, hyperosmotic solutions and capsaicin [32]. RICCIO et al. [33] found that afferent A $\delta$ fibres originating in the nodose ganglion, possibly identifiable with RARs, were not stimulated by capsaicin, but $75 \%$ of $A \delta$ fibres originating in the jugular ganglion could be activated by this compound. Their results suggest that the stimulation of guinea-pig airway afferent fibres by capsaicin is a function of their ganglionic origin rather than fibre characteristics. Analogous conclusions have been brought forward in a study on the responsiveness of RARs to capsaicin in cats. In fact, Moнамmed et al. [28] report-ed that some, but not all RARs challenged by inhaled capsaicin were stimulated, and suggested that "there are subpopulations of capsaicin-sensitive and -insensitive receptors".

In view of all the above results, which indicate a clear heterogeneity within the category of irritant receptors, there is no reason to expect a uniform responsiveness of RARs to moguisteine. Notwithstanding the fact that not all receptors were inhibited by moguisteine, our results provide additional supportive evidence for an antitussive action of this compound at the level of RAR endings. Considering the results of clinical trials and experimental data on animals of various species exposed to tussigenic stimuli, a convincing case can indeed be made in support of an antitussive action of moguisteine at the receptor level. The time course of its inhibitory effect on RAR activity, with a rapid onset and a relatively long-lasting action, should contribute to its therapeutic value. The findings of an inhibitory effect of moguisteine on inflammatory processes $[4,5]$, particularly at the airway levels, support the involvement of RARs in the mechanism of action of this antitussive compound. In fact, some of the components of inflammation, such as pulmonary congestion, microvascular leakage, mucus secretion, hyperreactivity to cigarette smoke, acetylcholine and histamine, are known to stimulate RARs located in large extrapulmonary bronchi and, thus, to elicit cough [34]. Thus, moguisteine seems to have a dual mechanism of action on RARs: a direct one, as suggested by the present study, as well as an 
indirect one mediated through its anti-inflammatory properties.

In summary, the results of the present investigation demonstrate that moguisteine, administered intravenously, has an inhibitory action on the activation of the majority of rapidly adapting irritant receptors studied, and support the hypothesis that this antitussive compound acts at the level of the rapidly adapting irritant receptors.

\section{References}

1. Gandolfi CA, Di Domenico R, Spinelli S, et al. N-acyl2-substitute-1,3-thiazolidines, a new class of non-narcotic antitussive agents: studies leading to the discovery of ethyl 2-[(2-methoxyphenoxy)methyl]- $\beta$-oxothiazolidine3-propanoate. J Med Chemistry 1995; 38: 508-525.

2. Gallico L, Borghi A, Dalla Rosa C, Lumachi B, Tofanetti O, Tognella S. BBR 2173, a new non narcotic antitussive agent. Pharmacol Res Commun 1988; 20: 171.

3. Gallico L, Borghi A, Dalla Rosa C, Ceserani R, Tognella S. Moguisteine: a novel peripheral non-narcotic antitussive drug. Br J Pharmacol 1994; 112: 795-800.

4. Gallico L, Borghi A, Dalla Rosa C, et al. Moguisteine: a new drug effective in experimental cough and hyperactivity. Am Rev Respir Dis 1990; 141: A654.

5. Gallico L, Oggioni N, Dalla Rosa C, Ceserani R, Tognella S. Effects of moguisteine, a peripheral nonnarcotic antitussive agent, on airway inflammation on guinea-pigs in vivo. Eur Respir J 1996; 9: 478-485.

6. Morrone L, Pizza A, Martinelli A, Merlo G, Maiorano V, Chianese R. Pilot study on efficacy and safety of a new antitussive drug, moguisteine: a double-blind, placebocontrolled trial. Adv Ther 1993; 10: 67-73.

7. Adams R, Hosie J, James I, et al. Antitussive activity and tolerability of moguisteine in patients with acute cough: a randomized, double-blind, placebo-controlled study. $A d v$ Ther 1993; 10: 263-271.

8. Aversa C, Cazzola M, Clini V, et al. A double-blind placebo controlled, parallel group clinical trial on efficacy and safety of moguisteine in patients with cough associated to chronic respiratory diseases. Drugs Exptl Clin Res 1993; 19: 273-279.

9. Fasciolo G, Nicolini A, Vacca N, Viglierchio P. Efficacy and safety of moguisteine in comparison with levodropropizine in patients with cough associated with chronic obstructive pulmonary disease, lung cancer or pulmonary fibrosis. Current Ther Res 1994; 55: 251-261.

10. Del Donno M, Aversa C, Corsico R, et al. Efficacy and safety of moguisteine in comparison with dextromethorphan in patients with persistent cough. Drug Invest 1994; 7: 93-100.

11. Barnabè R, Berni F, Clini V, et al. The efficacy and safety of moguisteine in comparison with codeine phosphate in patients with chronic cough. Monaldi Arch Chest Dis 1995; 50: 93-97.

12. Keller CJ, Loeser A. Der zentripetale Lungenvagus. $Z$ Biol 1929; 89: 373-395.

13. Knowlton GG, Larrabee MG. A unitary analysis of pulmonary volume receptors. Am J Physiol 1946; 147: 100-114.

14. Widdicombe JG. Receptors in the trachea and bronchi of the cat. J Physiol (Lond) 1954; 123: 71-104.

15. Kappagoda CP, Man GCW, Teo KK. Behaviour of canine pulmonary vagal afferent receptors during sustained acute pulmonary venous pressure elevation. J Physiol (Lond) 1987; 394: 249-265.

16. Mills JE, Sellick H, Widdicombe JG. Epithelial irritant receptors in the lungs. In: Porter R. Breathing: Hering
Breuer Centenary Symposium. London, Churchill, 1970; pp. 77-92.

17. Kaufman MP, Iwamoto GA, Ashton GH, Cassidy SS. Responses to inflation of vagal afferents with endings in the lungs of dogs. Circulation Res 1982; 51: 525-531.

18. Sant'Ambrogio G, Tsubone H, Sant'Ambrogio FB. Sensory information from the upper airway: role in the control of breathing. Respir Physiol 1995; 102: 1-16.

19. Mortola J, Sant'Ambrogio G, Clement MG. Localization of irritant receptors in the airways of the dog. Respir Physiol 1975; 24: 107-114.

20. Sant'Ambrogio G, Remmers GE, De Groot WJ, Callas G, Mortola JP. Localization of rapidly adapting receptors in the trachea and main stem bronchus of the dog. Respir Physiol 1978; 33: 359-366.

21. Sant'Ambrogio G. Information arising from the tracheobronchial tree of mammals. Physiol Rev 1982; 62: 531569.

22. Sant'Ambrogio G. Recettori nervosi delle vie aeree e dei polmoni. In: Grassi C, Muiesan G, eds. Terapia Pneumologica. Firenze, USES Edizioni Scientifiche, 1987; pp. 3-12.

23. Mills JE, Sellick H, Widdicombe JG. Activity of lung irritant receptors in pulmonary microembolism, anaphylaxis and drug-induced bronchoconstrictions. J Physiol (Lond) 1969; 203: 337-357.

24. Tatar M, Sant'Ambrogio G, Sant'Ambrogio FB. Laryngeal and tracheobronchial cough in anesthetized dogs. $J$ Appl Physiol 1994; 76: 2672-2679.

25. Lee B-P, Sant'Ambrogio G, Sant'Ambrogio FB. Afferent innervation and receptors of the canine extrathoracic trachea. Respir Physiol 1992; 90: 55-65.

26. Anderson JW, Sant'Ambrogio FB, Mathew OP, Sant' Ambrogio G. Water-responsive laryngeal receptors in the dog are not specialized endings. Respir Physiol 1990; 79: 33-44.

27. Coleridge HM, Coleridge JCG, Baker DG, Ginzel KH, Morrison MA. Comparison of the effects of histamine and prostaglandin on afferent $\mathrm{C}$-fiber endings and irritant receptors in the intrapulmonary airways. Adv Exptl Med Biol 1977; 99: 291-305.

28. Mohammed SP, Higenbottam TW, Adcock JJ. Effects of aerosol-applied capsaicin, histamine and prostaglandin $\mathrm{E}_{2}$ on airway sensory receptors of anaesthetized cats. $J$ Physiol (Lond) 1993; 469: 51-66.

29. Karlsson J-A, Sant'Ambrogio G, Widdicombe J. Afferent neural pathways in cough and reflex bronchoconstriction. J Appl Physiol 1988; 65: 1007-1023.

30. Ventresca PG, Nichol GM, Barnes PJ, Chung KF. Inhaled furosemide inhibits cough induced by low chloride content solutions but not by capsaicin. Am Rev Respir Dis 1990; 142: 143-146.

31. Sant'Ambrogio FB, Sant'Ambrogio G, Anderson JW. Effect of furosemide on the response of laryngeal receptors to low-chloride solutions. Eur Respir J 1993; 6: 1151-1155.

32. Fox AJ, Barnes PJ, Dray A. Stimulation of guinea-pig tracheal afferent fibres by nonisosmotic and low chloride stimuli and the effect of frusemide. J Physiol (Lond) 1995; 482: 179-187.

33. Riccio MM, Kummer W, Biglari B, Myers AC, Undem $\mathrm{BJ}$. Interganglionic segregation of distinct vagal afferent fiber phenotype in guinea-pig airways. $J$ Physiol (Lond) 1996; 496: 521-530.

34. Ravi K, Kappagoda CT, Bonham AC. Pulmonary congestion enhances responses of lung rapidly adapting receptors to cigarette smoke in rabbits. J Appl Physiol 1994; 77: 2633-2640. 